Volume 1, Nomor 1, September 2020, 33-38

BEMAS: JURNAL BERMASYARAKAT

p ISSN 2745-5866 | e ISSN xxxx xxxx

\title{
OLAHAN PISANG ULI MENJADI PISANG CRISPY
}

\author{
Muhammad Ilham Alhabsyie ${ }^{1}$, Awang Surya ${ }^{2 *}$, Aswin Domodite ${ }^{3}$ \\ 1,2*3 Program Studi Teknik Mesin, Sekolah Tinggi Teknologi Muhammadiyah Cileungsi, Bogor, Jawa Barat, \\ Indonesia 16820 \\ Email: ilham.alhabsyie186@gmail.com, *awang.surya.68@gmail.com,domodite@gmail.com
}

\author{
INFORMASI ARTIKEL \\ Article History: \\ Submission: 15-08-2020 \\ Revised: 25-09-2020 \\ Accepted: 26-09-2020 \\ Published: 30-09-2020 \\ * Korespondensi: \\ Awang Surya \\ awang.surya.68@gmail.com
}

\begin{abstract}
ABSTRAK
Pisang uli adalah jenis pisang yang banyak dijumpai di Indonesia terutama di Pulau Jawa. Pemanfaatannya selama ini selain dimakan secara langsung adalah diolah menjadi pisang goreng. Kegiatan yang dilakukan ini bertujuan mencari alternatif pengolahan dengan metode baru pisang uli yaitu dengan membuat pisang crispy dan tambahan topping. Metode yang dilakukan adalah dengan tahapan persiapan yaitu pengamatan singkat sumber-sumber pisang uli dan pemanfaatannya selama ini. Setelah itu pelaksanaan pembuatan pisang uli crispy. Hasil dari kegiatan ini disajikan dalam urutan proses produksi dan perhitungan biaya pembuatan pisang crispy yang bisa dimanfaatkan oleh warga Di Cileungsi dan sekitarnya.

\section{Kata kunci: Pisang Goreng, Pisang Crispy, Topping}

\begin{tabular}{l}
\hline ABSTRACT \\
\hline Uli banana is a type of banana that is often found in Indonesia, especially \\
on the island of Java. Besides being eaten directly, its use is processed into \\
fried bananas. This activity aims to find alternative processing with the \\
new method of uli banana, namely by making crispy bananas and \\
additional topping. The method used is the preparation stage, namely a \\
brief observation of the sources of uli bananas and their utilization so far. \\
After that, the implementation of making crispy uli bananas. The results of \\
this activity are presented in the order of the production process and the \\
calculation of the cost of making crispy bananas that can be used by \\
residents in Cileungsi and its surroundings.
\end{tabular}
\end{abstract}

Keywords: Fried Banana, Crispy Banana, Topping

\section{PENDAHULUAN}

Pisang dengan nama Latin Musa paradisiacal merupakan jenis buah-buahan tropis yang sangat banyak dihasilkan di Indonesia. Pulau Jawa dan Madura mempunyai kapasitas produksi kira-kira 180.153 ton per tahun.[1] Kapasitas produksi Provinsi Lampung sebanyak 1.438.559 ton. Tahun 2014 produksi pisang di Indonesia mencapai 7.008.407 ton (BPS, 2015). Produksi pisang di Indonesia yang cukup tinggi tidak sebanding dengan tingkat konsumsi masyarakat, sehingga mengakibatkan banyaknya pisang yang tidak dimanfaatkan karena daya simpan buah pisang yang relatif singkat.[2]

Pisang merupakan buah yang banyak dikonsumsi dalam bentuk segar. Permasalahan konsumsi pisang dalam bentuk segar sangat terbatas waktu.Buah pisang mudah rusak dan cepat mengalami 
perubahan mutu setelah panen, karena memiliki kandungan air tinggi dan aktivitas proses metabolismenya meningkat setelah dipanen.[3]

Pemanfaatan pisang selain dikonsumsi langsung setelah pisang masak, juga dapat diolah menjadi aneka pangan, seperti dodol pisang, keripik pisang, dan lain-lain. Penelitian dari Emaga et al. (2007) menyatakan bahwa kulit pisang mengandung serat pangan dalam jumlah $50 \mathrm{~g} / 100 \mathrm{~g}$, sehingga merupakan sumber serat pangan potensial.[4]

Manfaat buah pisang yang begitu besar bagi tubuh membuat pisang memiliki peluang usaha yang besar jika bisa diolah menjadi produk yang inovatif. Salah satunya adalah pisang crispy. Pisang crispy atau pisang renyah, merupakan pengolahan buah pisang yang mengembangkan makanan tradisional yaitu pisang goreng yang sudah populer di masyarakat. Dalam produksinya pisang crispy digoreng dengan tepung yang renyah dan disajikan dengan menambahkan topping diatasnya seperti keju, coklat atau susu.[5]

Ada beberapa jenis pisang yang dikenal di Indonesia di antaranya yaitu, pisang ambon, pisang uli, pisang raja, pisang kepok dan lain-lain. Dari beberapa jenis pisang, pisang uli cukup banyak dikonsumsi. Pisang ini sering dikonsumsi sebagai pisang goreng. Selain itu, pisang uli juga dijadikan bahan untuk membuat kue.

Buah pisang uli panjangnya kurang lebih $10 \mathrm{~cm}$ dan bentuknya bulat dengan ujung meruncing. Ukuran buahnya kecil dan langsing. Kulit buahnya tipis. Warna dagingnya putih atau kekuningan dan agak lembek. Rasanya manis beraroma harum. Kelebihan dari pisang uli dari jenis pisang yang lain adalah mudah diolah dan cocok untuk digoreng karena tidak semua jenis pisang cocok untuk digoreng. Selain itu pisang uli mudah ditemukan di pasar modern dan pasar tradisional.

Dengan kegiatan inovasi yaitu mengolah pisang uli menjadi pisang crispy ini diharapkan dapat meningkat nilai tambah dari buah pisang, sehingga bisa meningkatkan pendapatan bagi masyarakat terutama di desa Cipenjo, Kecamatan Cileungsi, Kabupaten Bogor.

\section{METODE}

Kegiatan inovasi mengolah pisang uli menjadi makanan kekinian pisang crispy ini dilakukan dengan tahapan sebagai berikut:

\section{A. Persiapan:}

- Pada tahapan persiapan ini dilakukan kunjungan sumber-sumber dan ketersediaan pisang uli di sekitar desa Cipenjo, Kecamatan Cileungsi, Kabupaten Bogor. Juga dilakukan wawancara dengan warga sekitar mengenai pengolahan pisang uli yang selama ini mereka lakukan. Selanjutnya dilakukan studi pengolahan pisang uli yang mudah dan menarik bagi kalangan pembeli masa kini yaitu dengan membuat pisang crispy.

B. Pelaksanaan

- Kegiatan inti adalah membuat pisang uli crispy. Setelah dilakukan percobaan pembuatan sampai kualitas bagus dan layak jual, maka diadakan perhitungan biaya untuk gambaran awal. Hasil dari kegiatan ini selanjutnya dituangkan ke dalam laporan agar bisa dimanfaatkan masyarakat yang berminat.

\section{HASIL DAN PEMBAHASAN}

\subsection{Alat}

Beberapa peralatan yang dipergunakan dalam kegiatan ini adalah sebagai berikut:

1. Wadah sebagai tempat menampung pisang yang diolah

2. Pisau untuk memotong buah pisang sesuai ukuran tertentu

3. Piring untuk membuat adonan 
4. Wajan untuk menggoreng pisang yang sudah diberi adonan

5. Paper lunch box menampung hasil produksi

\subsection{Bahan utama}

1. Pisang uli.

2. Tepung pisang goreng.

3. Tepung panir.

4. Air secukupnya.

5. Minyak goreng.

\subsection{Bahan Topping}

1. Coklat

2. Keju

3. Susu

\subsection{Cara Pembuatan}

Proses pembuatan pisang uli crispy mengikuti urutan sebagai berikut:

1. Siapkan tepung sasa pisang goreng dan air secukupnya dan buatlah adonan

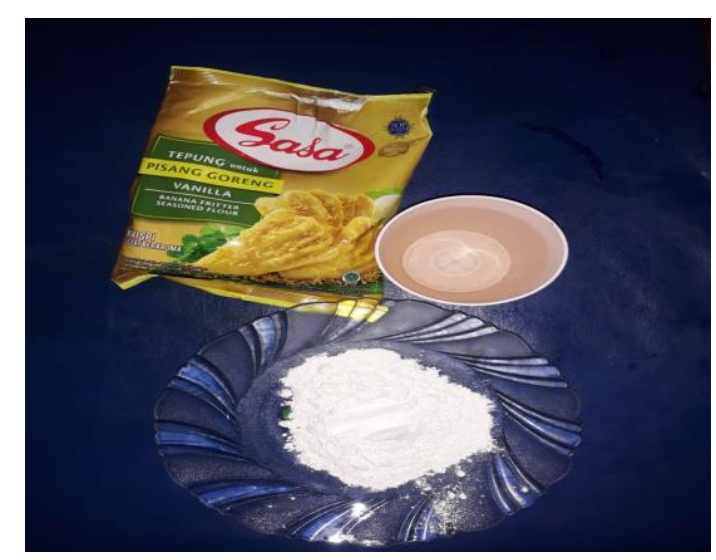

Gambar 1. Persiapan bahan untuk membuat adonan

2. Iris buah pisang terlebih dahulu menjadi 3 atau 2 bagian tergantung besarnya pisang.

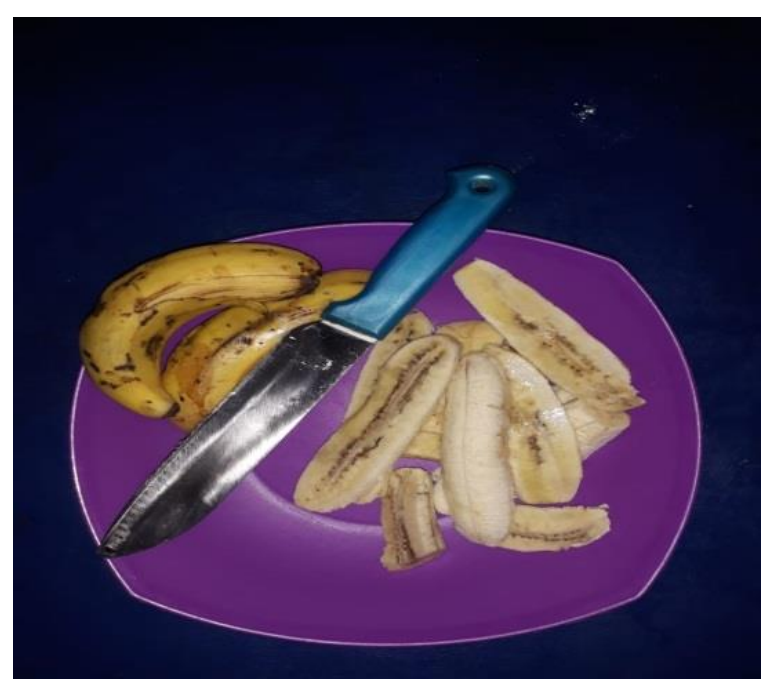

Gambar 2. Pisang sesudah di kupas 
3. Campurkan adonan pada gambar 1 dengan pisang yang sudah diiris dengan penjelasan gambar 2 hingga merata dan diamkan selama 30 detik hingga adonan meresap ke dalam pisang tersebut.

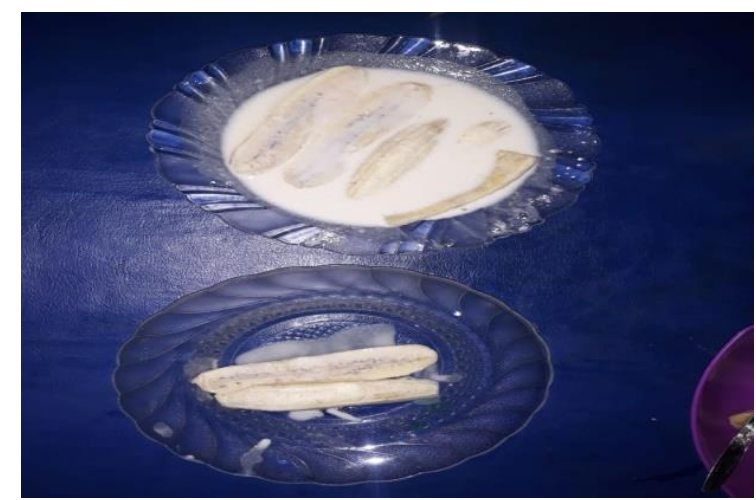

Gambar 3. Buah pisang dicampur dengan adonan

4. Siapkan tepung panir di dalam wadah dan campurkan dengan pisang yang sudah dicampurkan adonan yang dijelaskan pada gambar 4 .

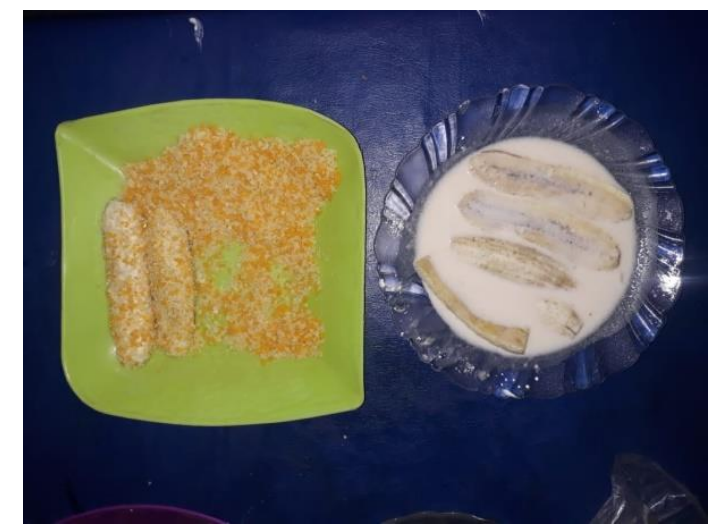

Gambar 4. Campuran adonan pisang bercampur dengan tepung panir

5. Siapkan wajan dan minyak secukupnya di atas kompor dengan keadaan api menyala.

6. Jika sudah maka masukan pisang tersebut (no.4) ke dalam minyak hingga pisang tersebut agak kekuningan.

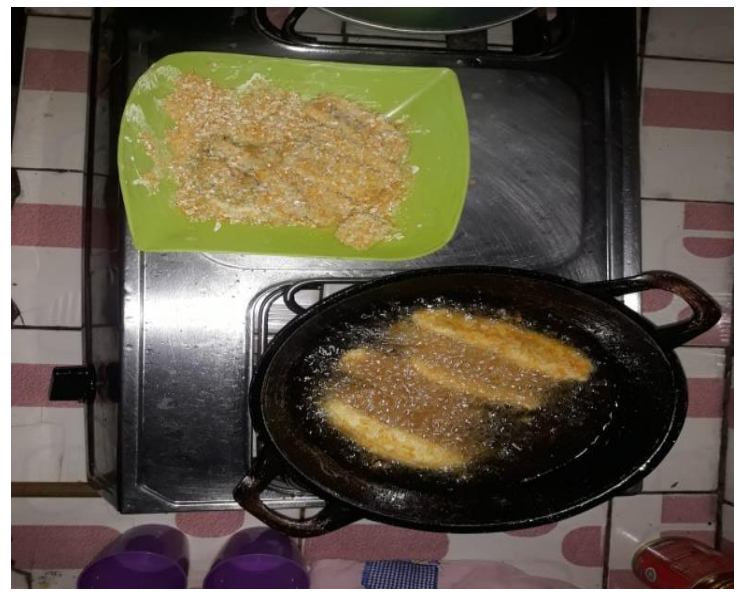

Gambar 5. Pisang di goreng di atas minyak panas hingga matang 
7. Siapkan paper lunch box.

Kemasan yang dipergunakan dalam pembungkusan pisang crispy ini harus menarik pelanggan, supaya produk yang dipasarkan lebih dikenal oleh masyarakat luas.

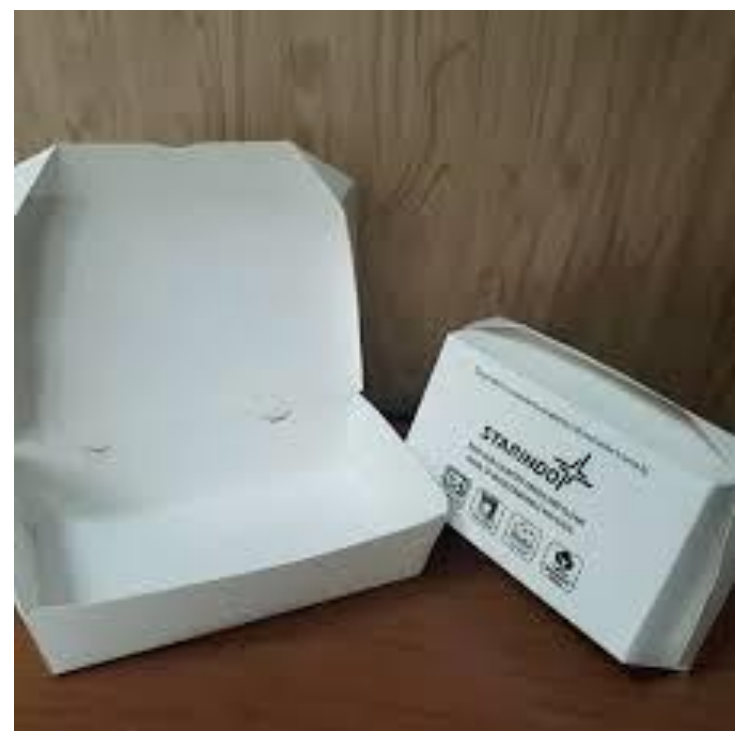

Gambar 6. Paper lunch Box.

8. Jika pisang sudah matang masukan pisang tersebut ke dalam paper lunch box ditata dengan rapi (pisang harus hangat atau panas)

9. Sesudah pisang tersebut ditata dengan rapi maka tinggal pemberian topping

10.Siapkan topping coklat (tergantung topping yang diinginkan / topping bebas)

11.Jika pisang sudah diberi topping maka tutup rapat paper lunch box tersebut hingga coklat di dalam meleleh dan diamkan hingga $2-3$ menit.

12.Jika sudah meleleh maka selanjutnya diberi susu vanila di atas topping tersebut.

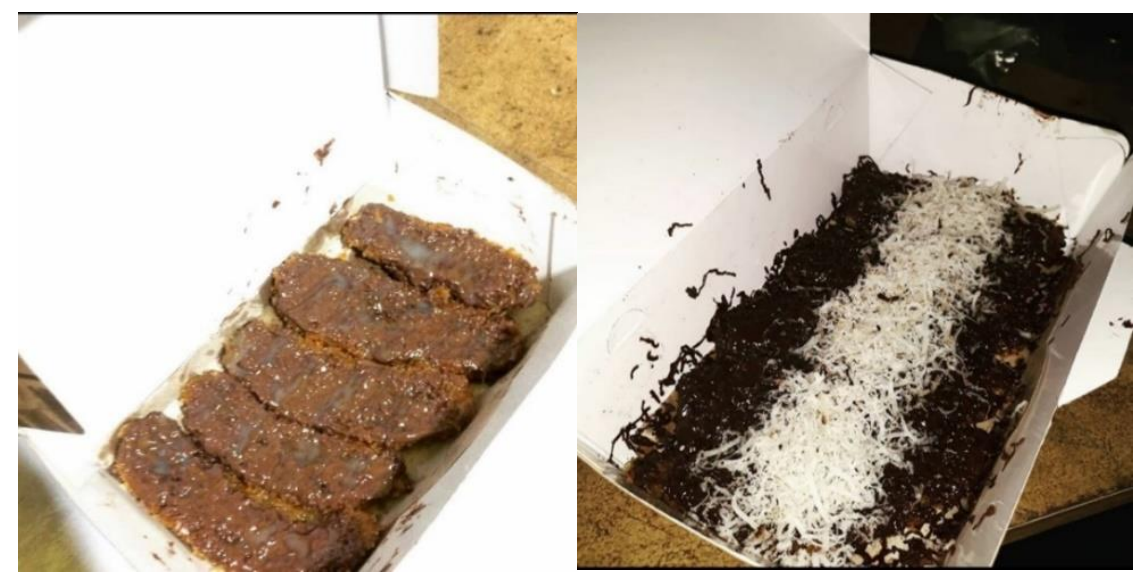

Gambar 8. Hasil olahan pisang Uli menjadi pisang Crispy Bertoping

Hal penting dari kegiatan ini adalah perhitungan biaya. Secara sederhana perhitungan biaya dari pembuatan pisang uli crispy adalah sebagai berikut.

Rincian biaya ini dimaksudkan memberi gamaran bagi masyarakat yang berniat menjadikan pisang uli crispy bertoping ini sebagai kegiatan usaha. Selanjutnya, masyarakat bisa melakukan inovasi sendiri kedepannya. 


\section{SIMPULAN}

Dari kegiatan yang dilaksanakan dapat disimpulkan beberapa hal, pisang uli bisa diolah menjadi makanan kekinian yaitu pisang crispy agar memberi nilai tambah. Kegiatan ini bisa menjadi sumber pendapatan bagi masyarakat terutama di tengah keadaan sulit seperti sekarang ini. Selanjutnya, perlu disosialisasikan hasil dari percobaan ini kepada masyarakat agar lebih banyak yang bisa mengambil manfaat.

\section{UCAPAN TERIMA KASIH}

Kami ucapkan terima kasih kepada dosen STTMC yang telah membimbing dalam hal penulisan artikel PkM, agar kedepannya lebih baik lagi dalam hal penulisan karya ilmiah.

\section{DAFTAR PUSTAKA}

[1] D. T. Retno and W. Nuri, "Pembuatan Bioetanol dari Kulit Pisang," Pros. Semin. Nas. Tek. Kim. "Kejuangan" Pengemb. Teknol. Kim. untuk Pengolah. Sumber Daya Alam Indones., 2011.

[2] "KARAKTERISTIK FISIKOKIMIA BISKUIT BERBAHAN BAKU TEPUNG PISANG GOROHO (Musa acuminate,sp)," COCOS, 2013.

[3] T. K. Putri et al., "Pemanfaatan jenis-jenis pisang (banana dan plantain) lokal Jawa Barat berbasis produk sale dan tepung," Kultivasi, 2015, doi: 10.24198/kltv.v14i2.12074.

[4] T. Aryani, I. A. U. Mu'awanah, and A. B. Widyantara, "Karakteristik Fisik, Kandungan Gizi Tepung Kulit Pisang dan Perbandingannya terhadap Syarat Mutu Tepung Terigu," JRST (Jurnal Ris. Sains dan Teknol., 2018, doi: 10.30595/jrst.v2i2.3094.

[5] D. P. Hapsari, D. Maulita, and N. Umdiana, "Peningkatan Ekonomi Rumah Tangga Dengan Pengolahan Pisang," KAIBON ABHINAYA J. Pengabdi. Masy., 2019, doi: 10.30656/ka.v1i2.1586. 